\title{
Author Correction: Enhancement of interlayer exchange in an ultrathin two-dimensional magnet
}

Dahlia R. Klein, David MacNeill, Qian Song, Daniel T. Larson, Shiang Fang (D), Mingyu Xu, R. A. Ribeiro (D), P. C. Canfield, Efthimios Kaxiras, Riccardo Comin (D) and Pablo Jarillo-Herrero (iD)

Correction to: Nature Physics https://doi.org/10.1038/s41567-019-0651-0, published online 16 September 2019.

In the version of this Letter originally published online, the descriptions of the pink and purple curves in Fig. 2a were switched in the caption; the text should have read "The data are taken at zero applied field (purple) and with an in-plane magnetic field of 2 T (pink)."

This has now been corrected in all versions.

Published online: 24 September 2019

https://doi.org/10.1038/s41567-019-0699-x

\section{Author Correction: Femtosecond-resolved observation of the fragmentation of buckminsterfullerene following $X$-ray multiphoton ionization}

N. Berrah (D), A. Sanchez-Gonzalez DD, Z. Jurek, R. Obaid D, H. Xiong, R. J. Squibb, T. Osipov, A. Lutman, L. Fang, T. Barillot, J. D. Bozek, J. Cryan, T. J. A. WolfD, D. Rolles, R. Coffee, K. Schnorr, S. Augustin, H. Fukuzawa (D), K. Motomura, N. Niebuhr (D, L. J. Frasinski, R. Feifel, C. P. Schulz, K. Toyota, S.-K. Son (D, K. Ueda, T. Pfeifer, J. P. Marangos (iD) and R. Santra (D)

Correction to: Nature Physics https://doi.org/10.1038/s41567-019-0665-7, published online 23 September 2019.

In the version of this Article originally published online, the following sentence was missing from the Acknowledgements: "Use of the Linac Coherent Light Source (LCLS), SLAC National Accelerator Laboratory, is supported by the US Department of Energy, Office of Science, Office of Basic Energy Sciences under contract no. DE-AC02-76SF00515." It has now been added. 